

\title{
A brief discussion on the tensile creep deformation behaviour of wrought single-phase $\gamma$-TiAl
}

\author{
Mainak Saha* \\ *Department of Metallurgical and Materials Engineering, National Institute of Technology (NIT) \\ Durgapur, India \\ mainaksaha1995@gmail.com \\ Corresponding author: Mainak Saha \\ Phone no: +918017457062
}

\begin{abstract}
Creep deformation behaviour in single phase $\gamma$-TiAl alloy has been an extensively studied topic since the late 1970s. A lot of literatures have reported creep behaviour of $\gamma$-TiAl alloys, manufactured using different processing techniques [1]-[7]. The present discussion revisits the original work on understanding the tensile creep deformation behaviour of wrought single-phase $\gamma$-TiAl alloy by Hayes et al. [8] and is aimed to develop an understanding of steady state creep, through strain vs strain rate and strain vs $\ln$ (strain rate) plots. Besides, it also attempts to study the variation of stress exponent with temperature between $760-900^{\circ} \mathrm{C}$ and also, to determine activation energies using the two most common approaches, namely: Zener-Hollomon (Z-H) [9] and Sherby-Dorn (S-D, temperature compensated time approach) [10] for stress levels of 69.4 and $103.4 \mathrm{MPa}$ between $760-900^{\circ} \mathrm{C}$.
\end{abstract}

Keywords: Apparent creep Activation energy, stress exponent, minimum strain rate, ZenerHollomon parameter, Sherby-Dorn parameter.

\section{Introduction}

A series of reports on room temperature tensile deformation behaviour of $\gamma$ - TiAl alloys show that the near- $\gamma$, two phase compositions having $\mathrm{Al}$ contents around 48 at.\% possess the highest strengths and ductilities [1]-[3], [11]-[18]. Extensive creep deformation studies have been carried out on a number of two phase near- $\gamma$ TiAI alloys produced by various processing routes [8], [19]-[29]. In addition, compression creep studies have been carried out on a number of binary single phase $\gamma$ TiAl alloys and a number of literatures have reported that minimum strain rates during creep testing at different regimes of temperature and stress, is hugely dependent on the grain size of materials [1], 
[8], [19], [30], [31]. Minimum strain rate of such intermetallic alloys may be defined in terms of Mukherjee-Bird-Dorn equation [32]-[34]. From a fundamental point of view, a study of the creep deformation behaviour of single phase TiAl is highly essential to provide useful insight into the deformation behaviour of the two phase TiAl alloys.

\subsection{Motivation}

The work of Hayes et al. [8] presents and discusses an analysis of the minimum strain rate deformation as well as an analysis of the tertiary creep behaviour of a wrought single phase $\gamma$-TiAl alloy within temperature range of $760-1000^{\circ} \mathrm{C}$ and stress range of $32-345 \mathrm{MPa}$. The analysis by Hayes et al. [8] was carried out through determination of apparent creep activation energies, at different temperature regimes, for various stresses, followed by theoretical calculation of stress exponents at different stress regimes, for different temperatures. This was followed by the prediction of the main mechanism for creep rupture at different temperatures, in a given stress range, using Monkmann-Grant (M-G) plots [9] and extensive microstructural characterisation using Optical microscope and the Transmission Electron Microscope (TEM) [8].

The present discussion revisits the original work by Hayes et al [8] and is aimed to develop an understanding of steady state creep, through strain rate vs strain and $\ln$ (strain rate) vs strain plots. Besides, it also attempts to (i) determine variation in stress exponent with temperature between 760$900^{\circ} \mathrm{C}$ and (ii) to determine activation energies through Zener-Hollomon (Z-H) and Sherby-Dorn (SD, temperature compensated time approach) for stress levels of 69.4 and 103.4 MPa between 760$900^{\circ} \mathrm{C}$. Some of the major claims of the work by Hayes et al. [8] are:

- Wrought single phase $\gamma$-TiAl alloy does not exhibit tertiary creep between $760-900{ }^{\circ} \mathrm{C}$, at stress levels of 69.4 MPa and 103.4 MPa.

- There is no steady state creep observed at $832^{\circ} \mathrm{C}$, at stress levels of $69.4 \mathrm{MPa}$, for both interrupted and uninterrupted tests.

- $\quad \gamma$-TiAl alloys do not exhibit dislocation creep at $760^{\circ} \mathrm{C}, 832^{\circ} \mathrm{C}$ and $900^{\circ} \mathrm{C}$ between stress level: 32-345 MPa.

\section{Discussion}

Table 1. Composition of the alloy (used by Hayes et al. [8]) 


\begin{tabular}{|l|l|l|l|l|l|l|l|l|}
\hline El. & $\mathrm{Ti}$ & $\mathrm{Al}$ & $\mathrm{Nb}$ & $\mathrm{Fe}$ & $\mathrm{H}$ & $\mathrm{O}$ & $\mathrm{N}$ & $\mathrm{C}$ \\
\hline at. $\%$ & 45.9 & 52.9 & 0.91 & 0.048 & 0.0219 & 0.1523 & 0.0026 & 0.0555 \\
\hline
\end{tabular}

Table 1. shows the composition of single phase $\gamma$-TiAl alloy, forged, heat treated and finally subjected to tensile creep testing, as discussed in the work of Hayes et al [8]. As discussed earlier, that only constructing strain vs time plot to determine "min. strain rate" and designating the same to be the "steady state strain rate", may be highly misleading for a number of materials, which do not exhibit steady-state creep [18]. Ti-53Nb-1Al, for instance, whether tested to rupture or terminated at midstrains of $0.18 \%$ and $0.5 \%$ at $832^{\circ} \mathrm{C}$, exhibited a very less amount of steady-state creep. In the case of creep test till rupture, significant primary creep is exhibited whereas, in the case of creep test terminated at $0.18 \%$ strain, there is no primary creep regime and for the creep test till $0.5 \%$ strain, the primary creep regime is in between the two aforementioned extremes. In all cases, there is a very early onset of tertiary creep, However, the rate of tertiary creep in all the three samples is significantly different, as indicated by slopes of plots in Figs. 3 (a) and (b). Besides, from Figs. 1(a) and (b), the strain rate as well as strain for initiation of tertiary creep in three samples, also vary, to a small extent, with the sample having terminating strain of $0.5 \%$ showing tertiary creep initiated at the lowest strain rate and the highest strain.
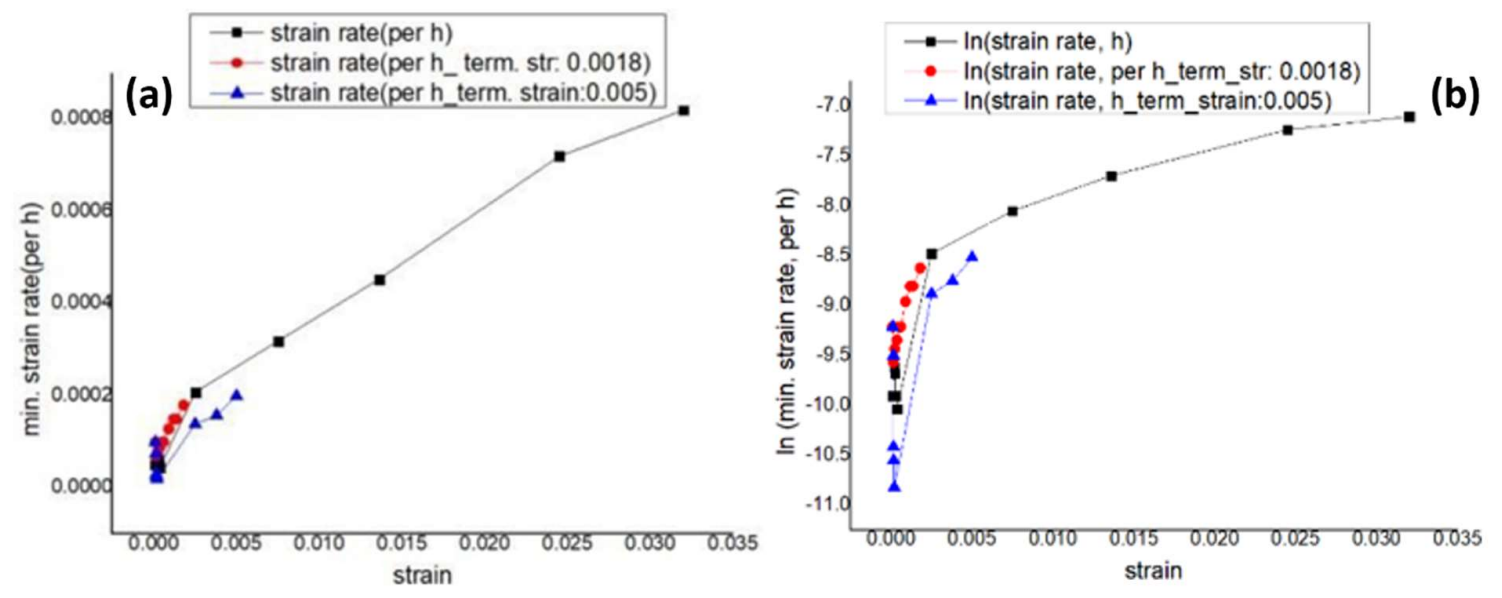

Fig. 1 (a) Strain rate vs Strain and (b) $\ln \left(\right.$ strain rate) vs strain plots at $832^{\circ} \mathrm{C}$ for sample subjected to interrupted tensile creep testing. 2 interruption (terminating) stresses were used by Hayes et al. [8] viz. $0.18 \%$ and $0.5 \%$ strain to fracture. 


\subsection{Determination of Activation energies between $760-1000^{\circ} \mathrm{C}$ at 69.4 and 103.4 MPa}
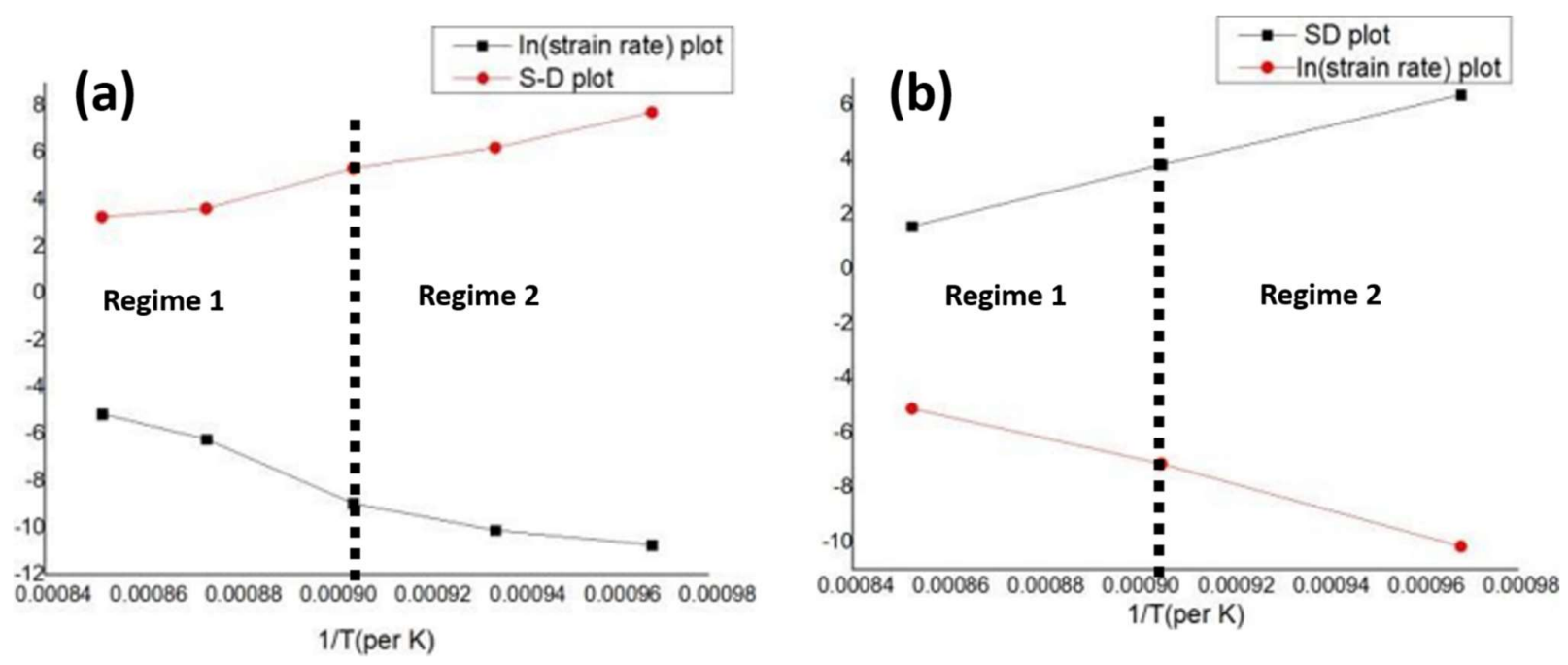

Fig 2. In (strain rate, in h) vs $1 / \mathrm{T}$ plot (marked as black) and Sherby -Dorn plot (marked as red) to determine creep activation energies at different temperature regimes at (a) $69.4 \mathrm{MPa}$ and (b) 103.4 $\mathrm{MPa}$.

\subsubsection{At 69.4 MPa}

From Fig 2(a), the apparent creep activation energies (determined from slope of black curve representing $\ln ($ strain rate, in h) vs $1 / \mathrm{T}$ at $69.4 \mathrm{MPa}$ ) vary from $423.92 \mathrm{~kJ} / \mathrm{mol}$ in regime 1 to 409.82 $\mathrm{kJ} / \mathrm{mol}$ in regime 2. Regimes 1 and 2 although seem to be independent [35], but the values of activation energies in two regimes, are found to be within experimental error. Moreover, the ZH (Zener Hollomon) parameter is obtained (from y-intercept of Fig. 2(a)) as 1.23e(14). Besides, Fig. 2(a) also shows rupture time vs $1 / \mathrm{T}$ plot (marked red) where SD parameter (determined from the $y$-intercept) is found to be $4.93 \mathrm{e}-14$ and apparent creep activation energy is determined (from slope of Fig. 2) as $329.03 \mathrm{~kJ} / \mathrm{mol}$. The transition temperature from Regime 1 to 2 is $\sim 838.11^{\circ} \mathrm{C}$.

\subsubsection{At 103.4 MPa}

From the $\ln ($ strain rate, in h) vs 1/T (per K) plot (marked as red in Fig 2(b)), ZH parameter (determined from y-intercept) is $1.11 \mathrm{e}(14)$ and apparent creep activation energies (determined from slope of $\ln ($ strain rate, in h) vs $1 / \mathrm{T}$ plot) vary from $364.77 \mathrm{~kJ} / \mathrm{mol}$ in regime 1 to $377.68 \mathrm{~kJ} / \mathrm{mol}$ in regime 2 . Regimes 1 and 2 are sequential [36]. 
Besides, Fig. 2(b) also shows rupture time vs 1/T plot (marked as black) where S-D parameter (SherbyDorn parameter, determined from y-intercept) is found to be 1.99e(-15) and Apparent Creep activation Energy (determined from slope) is found to be $345.65 \mathrm{~kJ} / \mathrm{mol}$. The transition temperature is decreased to $\sim 825.90^{\circ} \mathrm{C}$ about $14^{\circ} \mathrm{C}$ less than that at $69.4 \mathrm{MPa}$.

Table. 2 Grain boundary and lattice diffusion activation energies ( $\mathrm{Q}_{\mathrm{gb}}$ and $\mathrm{Q}_{\mathrm{L}}$ (in $\mathrm{kJ} / \mathrm{mol}$ ), respectively) at different test temperatures between 760 and $900^{\circ} \mathrm{C}$ and creep stresses of 69.4 and $103.4 \mathrm{MPa}$ following the work of Hayes et al [8]. $Q_{g b}$ and $Q_{L}$ have been calculated using Ashby's approach [9], [37].

\begin{tabular}{|l|l|l|l|l|}
\hline Temperature $\left({ }^{\circ} \mathrm{C}\right)$ & Stress $(\mathrm{MPa})$ & $\mathrm{Q}(\mathrm{kJ} / \mathrm{mol})$ & $\mathrm{Qgb}_{\mathrm{gb} / \mathrm{mol})}$ & $\mathrm{Q}_{\mathrm{L}}(\mathrm{kJ} / \mathrm{mol})$ \\
\hline 760 & 69.4 & 192 & 72 & 120 \\
\hline 760 & 103.4 & 304 & 114 & 190 \\
\hline 832 & 69.4 & 560 & 210 & 350 \\
\hline 832 & 103.4 & 405 & 151.88 & 253.13 \\
\hline 900 & 69.4 & 624 & 234 & 390 \\
\hline 900 & & & & 324.38 \\
\hline
\end{tabular}

It is observed that at 832 and $900^{\circ} \mathrm{C}$, with increase in stress level from 69.4 to $103.4 \mathrm{MPa}$, there is a decrease in apparent creep activation energy, but the reverse trend is observed at $760^{\circ} \mathrm{C}$. This is subject to further investigations using microstructural investigation at $760^{\circ} \mathrm{C}$, but is beyond the scope of discussion of the present work. 


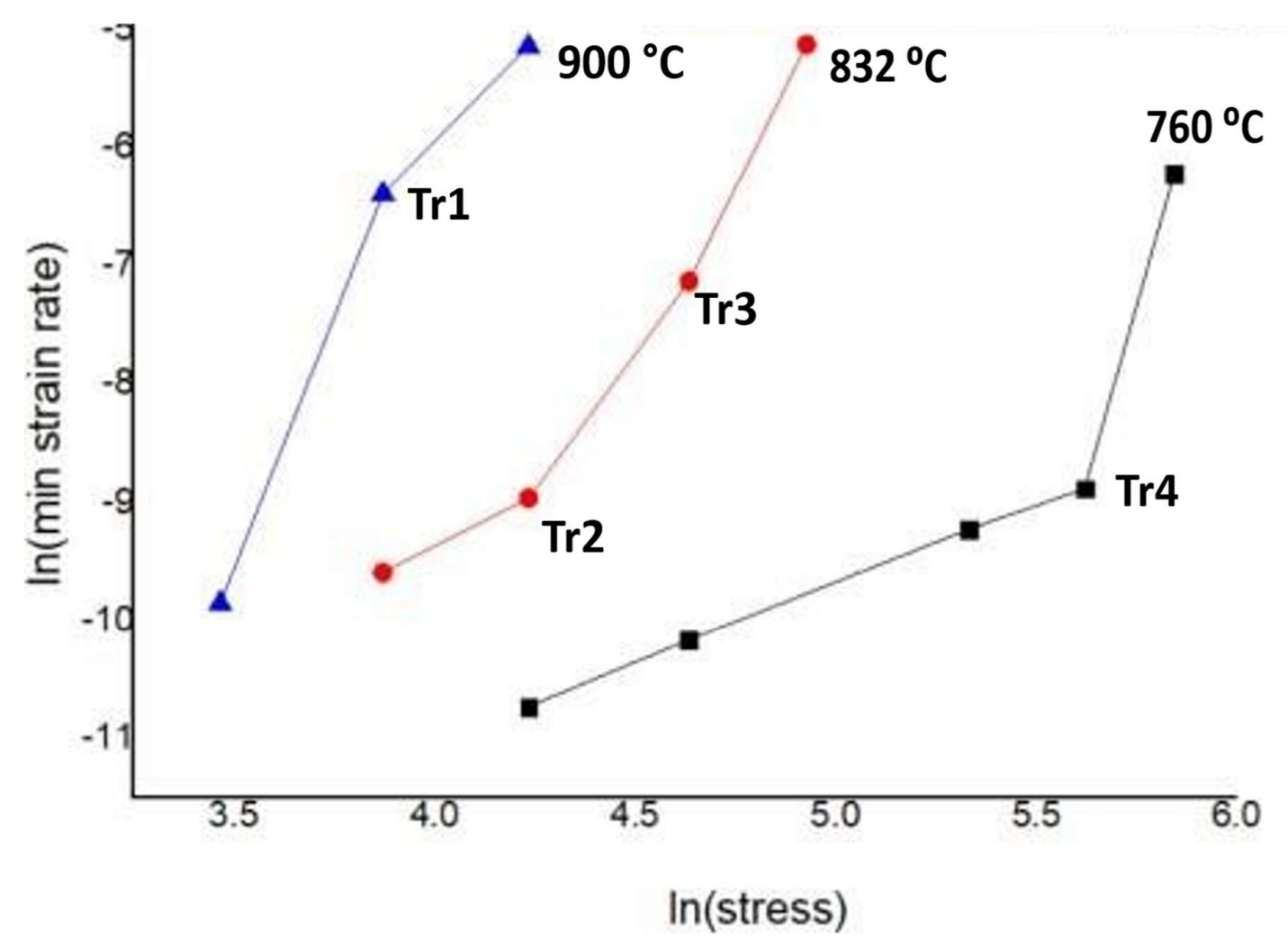

Fig. $3 \ln$ (min strain rate) vs strain plots at 760,832 and $900^{\circ} \mathrm{C}$

\subsection{Plots for determining stress exponent at 760,832 and $900^{\circ} \mathrm{C}$}

The plot (Fig. 3 ) for $760^{\circ} \mathrm{C}$ (black curve) shows that processes in 2 regimes must be independent. At $\operatorname{Tr} 1: 244.69 \mathrm{MPa}$, the plot suggests that there is transition from dislocation glide controlled creep to dislocation climb controlled creep [36], [38]-[43], suggesting a minor microstructural change leading to a change in creep deformation behaviour.

Based on the red coloured plot at $832^{\circ} \mathrm{C}$ (Fig. 3): (i) regime 1 (from beginning to point $\mathrm{Tr}$ 2) Stress exponent (from slope): 3; (ii) regime 2 (from points $\operatorname{Tr} 2$ to $\operatorname{Tr} 3$ ), Stress exponent: 4; (iii) regime 3 (from point $\operatorname{Tr} 3$ to end), Stress exponent: 4. Moreover, the red plot(in Fig. 3) also suggests that the cree mechanisms operating at 3 aforementioned regimes are independent. At $\operatorname{Tr} 2: 66.68 \mathrm{MPa}$ there is transition from dislocation glide controlled creep to dislocation climb controlled which again suggests that there is change in mechanism in Dislocation creep due to minor microstructural changes.

Based on the blue coloured plot at $900^{\circ} \mathrm{C}$ (Fig. 3): (i) regime 1 (from beginning to $\mathrm{Tr}$ ): stress 
exponent: 5 and (ii) regime 2 (from Tr4 to end): stress exponent: 4 . This suggests that power law creep [44] is continued but with a different slope (stress exponent) which again suggests transition from dislocation climb to dislocation glide controlled creep and thus, no major microstructural change.

2.3 Prediction of creep life using Larson-Miller (L-M) [45] and Manson-Haferd (M-H) [46] parameters

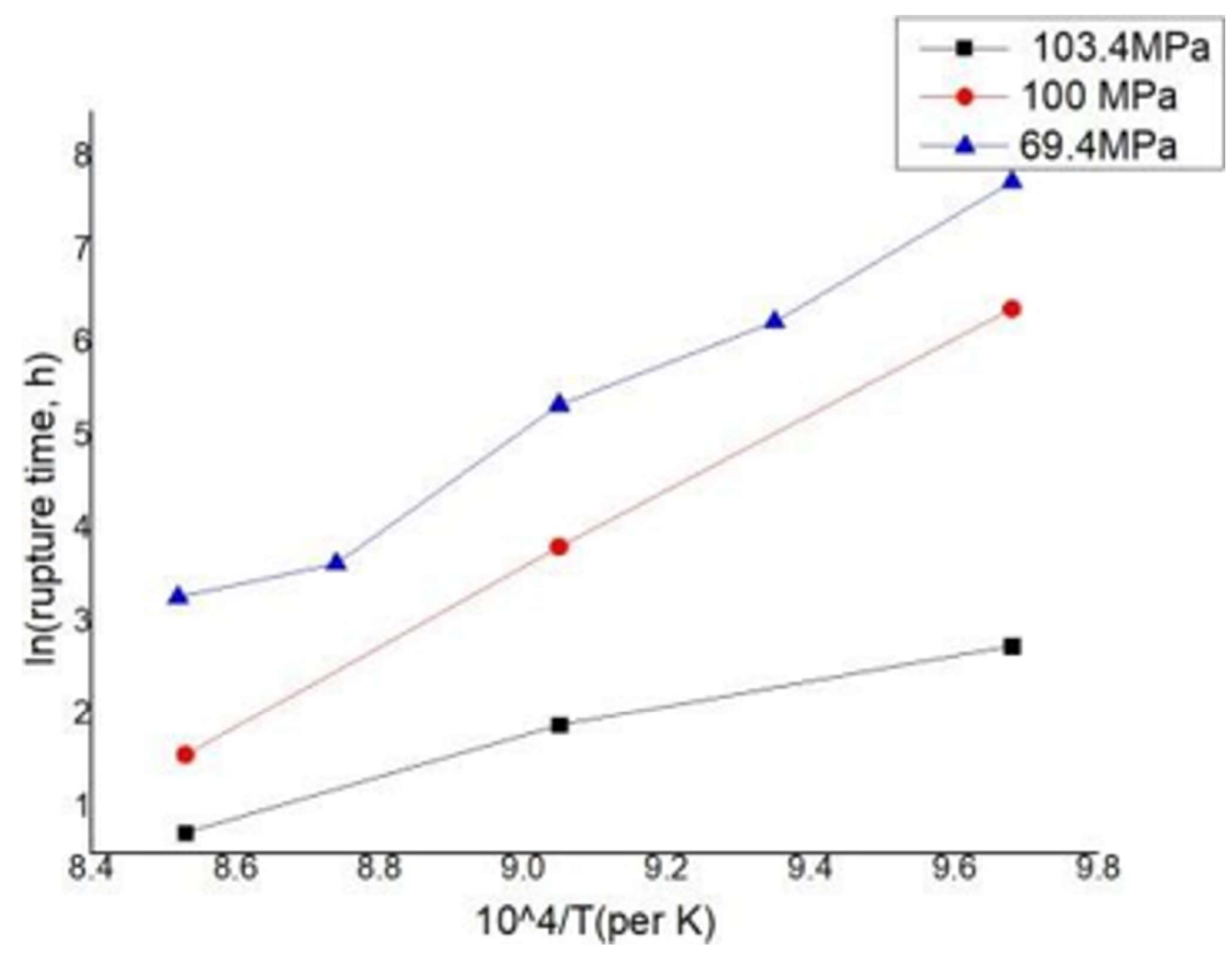

Fig. 4 Larson-Miller (L-M) plots at applied stresses of 69.4, 100 and 103.4 MPa

From Fig. 4, it may be inferred that creep life of the alloy decreases, due to onset of creep rupture [45]-[47], with increase in stress between 69.4-103.4 MPa and temperatures between 760-900 ${ }^{\circ}$. Table. 3 shows Larson-Miller (L-M) constants and parameters at 69.4, 100 and 103.4 MPa between 760-900 ${ }^{\circ}$ C. It may be observed from Table 2. that with increase in stress levels from 69.4-103.4 MPa, both L-M constants and parameters increase between $760-900^{\circ} \mathrm{C}$. 
Table. 3 Larson-Miller constants and parameters at $69.4,100$ and $103.4 \mathrm{MPa}$ between $760-900^{\circ} \mathrm{C}$.

\begin{tabular}{|l|l|l|}
\hline Stress (MPa) & L-M constant (K) & L-M Parameter \\
\hline 69.4 & 1.74 & 14.05 \\
\hline 100 & 3.96 & 30.64 \\
\hline 103.4 & 4.15 & 34.02 \\
\hline
\end{tabular}

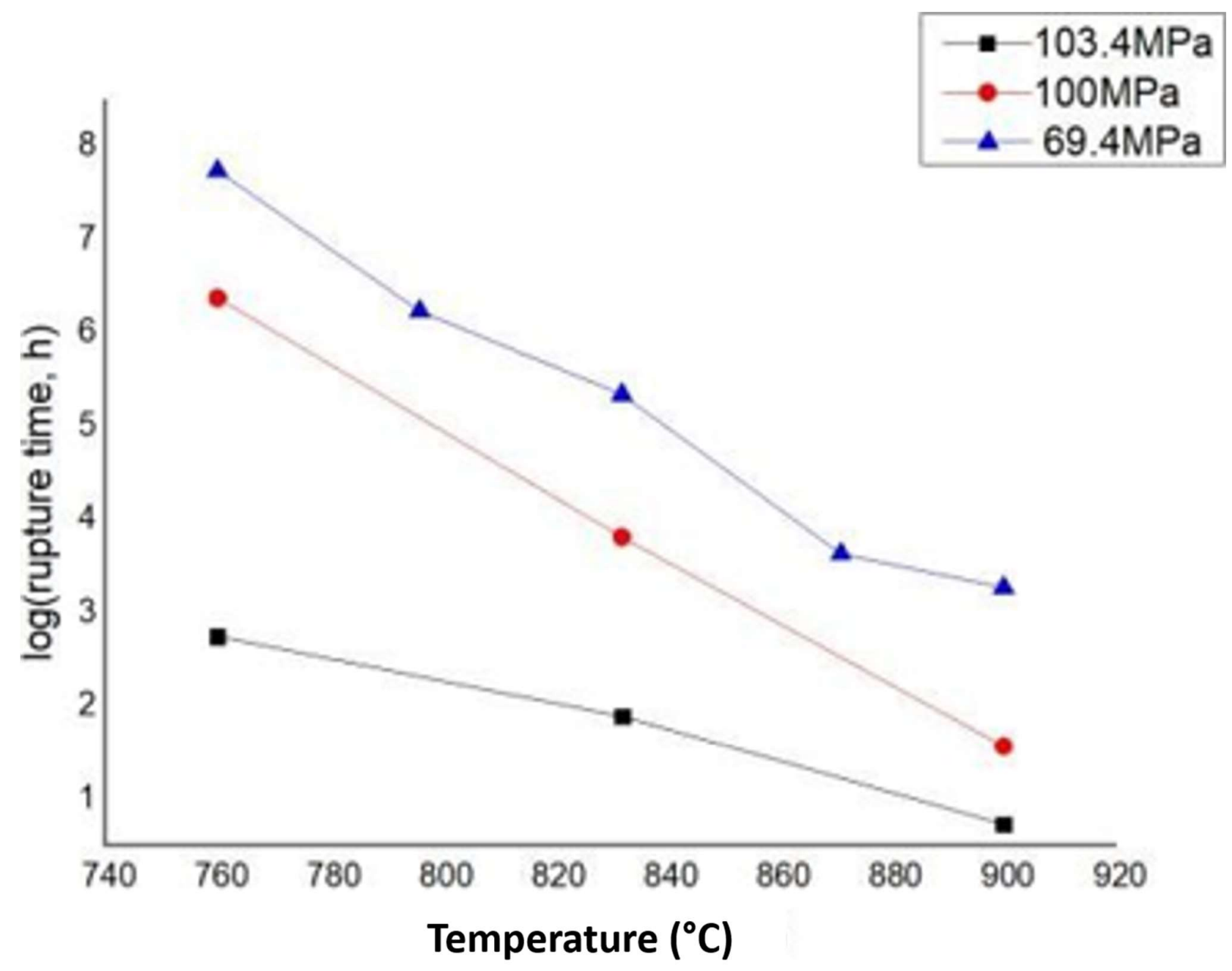

Fig. 5 Variation of $\log \left(\right.$ rupture time, h) with temperature $\left({ }^{\circ} \mathrm{C}\right)$ between $760-900^{\circ} \mathrm{C}$, at applied creep stress levels of 69.4 (blue), 100 (red) and 103.4 MPa (black).

Based on linear interpolation from Fig. 5, the M-H parameter at Stresses: 69.4 MPa, $100 \mathrm{MPa}$ and 
103.4 MPa may be calculated to be equal to $-0.033,-0.031$ and -0.014 , respectively.

2.4 Prediction of creep life using modified Monkman-Grant (M-G) parameter [9], [48]-[52]

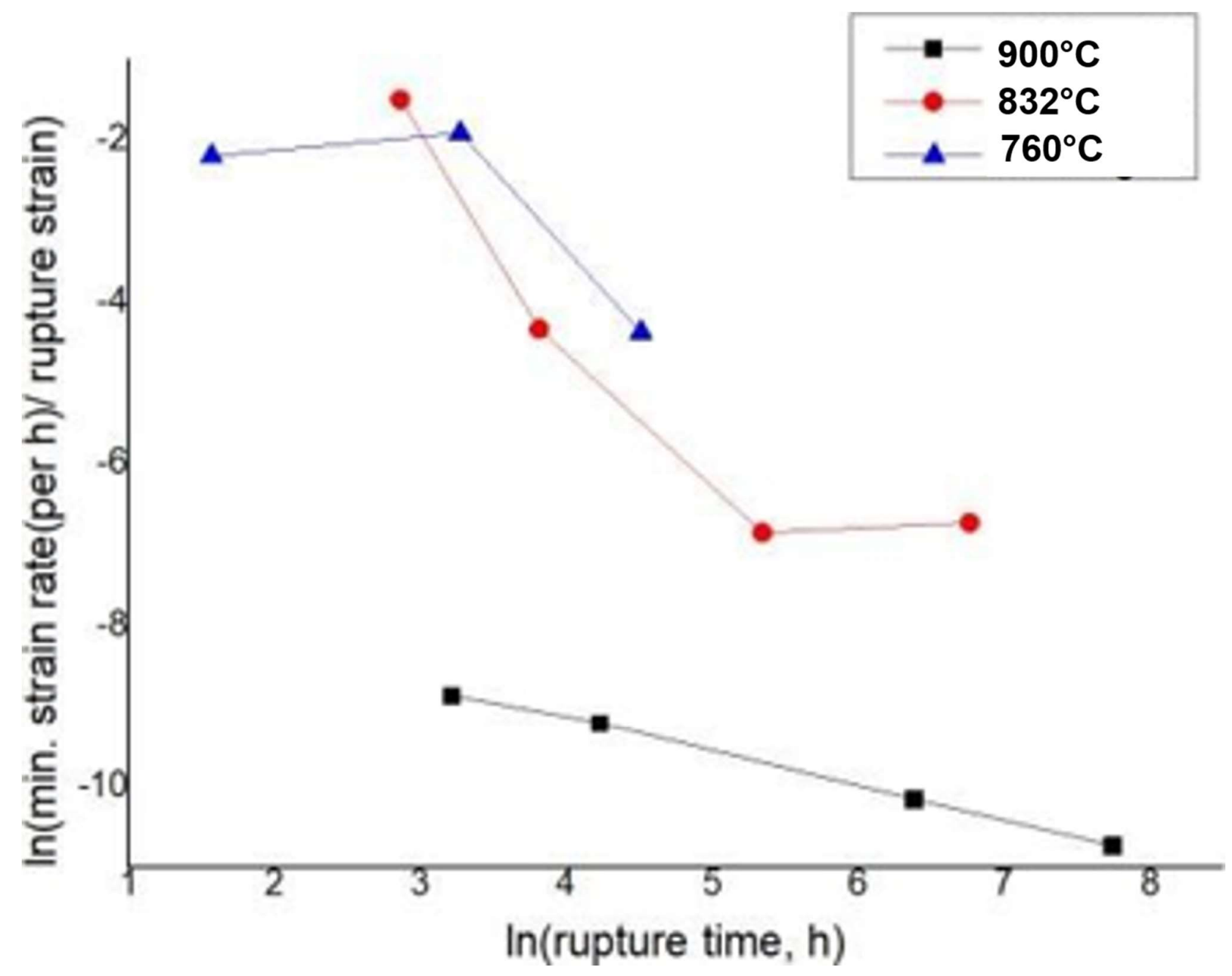

Fig. 6 Modified Monkman-Grant (M-G) parameter at 760, 832 and $900^{\circ} \mathrm{C}$.

Table. 4 M-G plot vs modified M-G plot (considering linear fit throughout entire creep life) at 760, 832 and $900^{\circ} \mathrm{C}$. where $\mathrm{p}, \mathrm{C}$ and $\mathrm{R}^{2}$ abbreviate for $\mathrm{M}-\mathrm{G}$ exponent; $\mathrm{M}-\mathrm{G}$ intercept and Goodness of fit, respectively. 


\begin{tabular}{|l|l|l|l|l|l|l|}
\hline T $\left({ }^{\circ} \mathrm{C}\right)$ & P (M-G) & C (M-G) & $\mathrm{R}^{2}(\mathrm{M}-\mathrm{G})$ & $\begin{array}{l}\text { P } \\
\text { (modified } \\
\text { M-G) }\end{array}$ & $\begin{array}{l}\text { C } \\
\text { (modified } \\
\text { M-G) }\end{array}$ & $\begin{array}{l}\mathrm{R}^{2} \text { (modified } \\
\text { M-G) }\end{array}$ \\
\hline 760 & -1.4 & 1.43 & 0.96 & -1.56 & 1.61 & 0.97 \\
\hline 832 & -1.3 & 1.31 & 0.93 & -1.33 & 1.40 & 0.98 \\
\hline 900 & -0.4 & 0.52 & 0.99 & -0.68 & 0.69 & 0.99 \\
\hline
\end{tabular}

From Fig. 6 and Table. 4, it may be observed that predominant creep rupture mechanism is power law breakdown [18] at 760 and $832^{\circ} \mathrm{C}$, due to $\mathrm{p}$ being greater than -1.4 but at $900^{\circ} \mathrm{C}$, owing to $\mathrm{p}$ equal to 0.4 , the predominant creep rupture mechanism requires further microstructural investigation and detailed analysis which is beyond the scope of the present study [53]-[55]. Besides, it may also be observed that using modified M-G plots, the goodness of fit is much improved than using the original M-G plots, implying that use of modified M-G plots improves data reliability [56].

\section{Conclusions}

Contradicting the claims of Hayes et al. [8], the various plots (Figs. 1-6), in the present discussion suggest that:

- Creep life between $760-900{ }^{\circ} \mathrm{C}, 69.4 \mathrm{MPa}$ and 103.4 MPa is dominated hugely by tertiary creep.

- Hardly, any Steady state is observed at $832^{\circ} \mathrm{C}, 69.4 \mathrm{MPa}$, for interrupted tensile creep tests.

- Dislocation creep tends to be the main deformation mechanism for these alloys at $760^{\circ} \mathrm{C}$, $832^{\circ} \mathrm{C}$ and $900^{\circ} \mathrm{C}$ between $32-345 \mathrm{MPa}$.

- Creep life of the alloy decreases, due to onset of creep rupture, with increase in stress between 69.4-103.4 $\mathrm{MPa}$ and temperatures between $760-900^{\circ} \mathrm{C}$. 


\section{Future scope of the work}

A small attempt has been made to revisit the understanding in terms of creep behaviour in Ti-53Nb-1 Al through strain rate vs strain plots, followed by determination of activation energies and stress exponents for different temperature and stress regimes, based on the work already performed by Hayes et al. [8]. However, extensive microstructural characterisation is required in order to study changes in microstructure, associated with variation in apparent creep activation energies in different temperature regimes and variation of stress exponent in different stress regimes. Besides, the effect of grain size on creep behavior of the alloy also needs to be studied in great details.

\section{Acknowledgement}

MS would like to thank the Department of Metallurgical and Materials Engineering, NIT Durgapur, for detailed discussions during the scripting of the brief discussion.

\section{References}

[1] J. Bieske, M. Franke, M. Schloffer, C. Körner. Intermetallics, "Microstructure and properties of TiAl processed via an electron beam powder bed fusion capsule technology," Elsevier, Accessed: Sep. 16, 2020 [Online]. Available: https://www.sciencedirect.com/science/article/pii/S0966979520304702.

[2] M. Ilyas, M. Rizviul Kabir. Materials Science and Engineering A, "Modelling high temperature deformation of lamellar TiAl crystal using strain-rate enhanced crystal plasticity," Elsevier, Accessed: Sep. 16, 2020. [Online]. Available: https://www.sciencedirect.com/science/article/pii/S0921509320305955.

[3] F. Zhao, J. Zhang, C. He, Y. Zhang, X. Gao, and L. Xie, "Molecular Dynamics Simulation on Creep Behavior of Nanocrystalline TiAl Alloy,” mdpi.com, doi: 10.3390/nano10091693. 
[4] N. Neelam, S. Banumathy, G. V. S Nageswara Rao, A. Bhattacharjee. Materials Today Proceedings, "Study of microstructure and mechanical properties of $\gamma$-Ti-46.5 Al-2Cr-(3.5 \& 5.0) Nb alloys," Elsevier, Accessed: Sep. 16, 2020. [Online]. Available: https://www.sciencedirect.com/science/article/pii/S2214785320352226.

[5] V. Singh, C. Mondal, R. Sarkar, P.P. Bhattacharjee, P. Ghoshal, Materials Science and Engineering A, "Compressive creep behavior of a $\gamma$-TiAl based Ti-45Al-8Nb-2Cr-0.2 B alloy: The role of $\beta$ (B2)-phase and concurrent phase transformations," Elsevier, Accessed: Sep. 16, 2020. [Online]. Available: https://www.sciencedirect.com/science/article/pii/S0921509319316715.

[6] Z. Duan, Y. Han, X. Song, H. Chen. Materials Science and Technology, "Creep behaviour of equiaxed fine-grain $\gamma$-TiAl-based alloy prepared by powder metallurgy," Taylor $\&$ Francis, Accessed: Sep. $\quad 2020$ [Online]. Available: https://www.tandfonline.com/doi/abs/10.1080/02670836.2020.1790098.

[7] X. Xinxin, D. Wenfeng, W. Zhixin, L. ANGGEI. Chinese Journal of Aeronautics, "Performance evaluation of creep feed grinding of $\gamma$-TiAl intermetallics with electroplated diamond wheels," Elsevier, Accessed: Sep. 16, 2020. [Online]. Available: https://www.sciencedirect.com/science/article/pii/S1000936120302636.

[8] R. W. Hayes and P. L. Martin, "Tension creep of wrought single phase $\gamma$ TiAl," Acta Metallurgica Et Materialia, vol. 43, no. 7, pp. 2761-2772, Jul. 1995, doi: 10.1016/09567151(94)00486-2.

[9] C. Zener and J. H. Hollomon, "Effect of strain rate upon plastic flow of steel," Journal of Applied Physics, vol. 15, no. 1, pp. 22-32, 1944, doi: 10.1063/1.1707363.

[10] R. Orr, O. Sherby, and J. Dorn, "Correlations of rupture data for metals at elevated temperatures," 1953, Accessed: Sep. 16, 2020. [Online]. Available: https://www.osti.gov/servlets/purl/4425999. 
[11] J. Zhang, X. Li, D. Xu, R. Yang. Progress in Natural Science: Materials International , "Recent progress in the simulation of microstructure evolution in titanium alloys," [Online]. Available: https://www.sciencedirect.com/science/article/pii/S1002007119303557.

[12] S. Saeedipour, A. Kermanpur. Journal of Materials Engineering and Performance, "On the Microstructure and Solidification Behavior of N-Bearing Ti-46Al-8Ta (at.\%) Intermetallic Alloys," Springer, Accessed: Sep. 16, 2020. [Online]. Available: https://link.springer.com/article/10.1007/s11665-019-04372-w.

[13] L. Chen, T. E. James Edwards, F. di Gioacchino, W. J. Clegg, F. P. E. Dunne, and M.-S. Pham, "Crystal plasticity analysis of deformation anisotropy of lamellar TiAl alloy: 3D microstructurebased modelling and in-situ micro-compression.” Accessed: Sep. 16, 2020. [Online]. Available: https://www.sciencedirect.com/science/article/pii/S0749641919300026.

[14] P. M. Hazzledine, "Coherency and loss of coherency in lamellar Ti-A1," Intermetallics, vol. 6, no. 7-8, pp. 673-677, 1998, doi: 10.1016/s0966-9795(98)00034-х.

[15] Y. Estrin and H. Mecking, "A unified phenomenological description of work hardening and creep based on one-parameter models," Acta Metallurgica, vol. 32, no. 1, pp. 57-70, 1984, doi: 10.1016/0001-6160(84)90202-5.

[16] L. M. Hsiung and T. G. Nieh, "Creep deformation of fully lamellar TiAl controlled by the viscous glide of interfacial dislocations," Intermetallics, vol. 7, no. 7, pp. 821-827, 1999, doi: 10.1016/S0966-9795(98)00135-6.

[17] J. N. Wang and T. G. Nieh, "The role of ledges in creep of TiAl alloys with fine lamellar structures," Acta Materialia, vol. 46, no. 6, pp. 1887-1901, Mar. 1998, doi: 10.1016/S13596454(97)00434-5. 
2015.

[19] R. W. Hayes and B. London, "On the creep deformation of a cast near gamma TiAl alloy Ti48Al1 Nb,” Acta Metallurgica Et Materialia, vol. 40, no. 9, pp. 2167-2175, 1992, doi: 10.1016/09567151(92)90134-Z.

[20] S. Karthikeyan, G. B. Viswanathan, P. I. Gouma, V. K. Vasudevan, Y. W. Kim, and M. J. Mills, "Mechanisms and effect of microstructure on creep of TiAl-based alloys," Materials Science and Engineering A, vol. 329-331, pp. 621-630, Jun. 2002, doi: 10.1016/S0921-5093(01)01659-8.

[21] A. Chatterjee, H. Mecking, E. Arzt, and H. Clemens, "Creep behavior of $\gamma$-TiAl sheet material with differently spaced fully lamellar microstructure," Materials Science and Engineering A, vol. 329331, pp. 840-846, Jun. 2002, doi: 10.1016/S0921-5093(01)01639-2.

[22] T. E. J. Edwards et al., "Deformation of lamellar $\gamma$-TiAl below the general yield stress," Acta Materialia, vol. 163, pp. 122-139, Jan. 2019, doi: 10.1016/j.actamat.2018.09.061.

[23] Y. W. Kim, "Intermetallic alloys based on gamma titanium aluminide," JOM, vol. 41, no. 7, pp. 24-30, Jul. 1989, doi: 10.1007/BF03220267.

[24] Y. Mishin and C. Herzig, "Diffusion in the Ti-Al system," Acta Materialia, vol. 48, no. 3. Elsevier Ltd, pp. 589-623, Feb. 09, 2000, doi: 10.1016/S1359-6454(99)00400-0.

[25] K. Maruyama, R. Yamamoto, H. Nakakuki, and N. Fujitsuna, "Effects of lamellar spacing, volume fraction and grain size on creep strength of fully lamellar TiAl alloys," Materials Science and Engineering A, vol. 239-240, no. 1-2, pp. 419-428, 1997, doi: 10.1016/s0921-5093(97)00612-6.

[26] H. S. Park, S. W. Nam, N. J. Kim, and S. K. Hwang, "Refinement of the lamellar structure in TiAl-based intermetallic compound by addition of carbon," Scripta Materialia, vol. 41, no. 11, pp. 1197-1203, 1999, doi: 10.1016/S1359-6462(99)00266-3. 
[27] J. Beddoes, W. Wallace, and L. Zhao, "Current understanding of creep behaviour of near $\gamma$ titanium aluminides," International Materials Reviews, vol. 40, no. 5, pp. 197-217, Jan. 2012, doi: $10.1179 / 095066095790151151$.

[28] M. Castillo-Rodríguez, M. L. Nó, J. A. Jiménez, O. A. Ruano, and J. San Juan, "High temperature internal friction in a Ti-46Al-1Mo-0.2Si intermetallic, comparison with creep behaviour," Acta Materialia, vol. 103, pp. 46-56, Jan. 2016, doi: 10.1016/j.actamat.2015.09.052.

[29] W. Schillinger, H. Clemens, G. Dehm, and A. Bartels, "Microstructural stability and creep behavior of a lamellar $\gamma$-TiAl based alloy with extremely fine lamellar spacing," Intermetallics, vol. 10, no. 5, pp. 459-466, 2002, doi: 10.1016/S0966-9795(02)00021-3.

[30] D. Banerjee and J. C. Williams, "Perspectives on titanium science and technology," Acta Materialia, vol. 61, no. 3, pp. 844-879, Feb. 2013, doi: 10.1016/j.actamat.2012.10.043.

[31] C. Y. Teng, A. Du, D. S. Xu, Y. Wang, and R. Yang, "Effect of external stress on $\gamma$ nucleation and evolution in TiAl alloys," Intermetallics, vol. 65, pp. 1-9, May 2015, doi: 10.1016/j.intermet.2015.05.003.

[32] J. Bird, A. Mukherjee, J. E Dorn, Israel Universities Press, Jerusalem, 1969, “Quantitative relation between properties and microstructure,” Accessed: Sep. 16, 2020. [Online].

[33] A. Mukherjee, R. Mishra, T. R Bieler, "Some critical aspects of high strain rate superplasticity," Trans Tech Publ, Accessed: Sep. 16, 2020. [Online]. Available: https://www.scientific.net/MSF.233-234.217.pdf.

[34] R. Mishra, A. Mukherjee. Materials Science and Engineering A, "The rate controlling deformation mechanism in high strain rate superplasticity," Elsevier, Accessed: Sep. 16, 2020. [Online]. Available: https://www.sciencedirect.com/science/article/pii/S0921509397003213. 
[35] W. Zhang, X. Wang, Y. Wang, X. Yu, Y. Gao, and Z. Feng, "Type IV failure in weldment of creep resistant ferritic alloys: II. Creep fracture and lifetime prediction,” Journal of the Mechanics and Physics of Solids, vol. 134, p. 103775, Jan. 2020, doi: 10.1016/j.jmps.2019.103775.

[36] A. H. Chokshi, "Grain Boundary Processes in Strengthening, Weakening, and Superplasticity," Advanced Engineering Materials, vol. 22, no. 1, p. 1900748, Jan. 2020, doi: 10.1002/adem.201900748.

[37] J. Weertman, “Zener-Stroh crack, Zener-Hollomon parameter, and other topics," Journal of Applied Physics, vol. 60, no. 6, pp. 1877-1887, Sep. 1986, doi: 10.1063/1.337236.

[38] R. R. Eleti, A. H. Chokshi, A. Shibata, and N. Tsuji, "Unique high-temperature deformation dominated by grain boundary sliding in heterogeneous necklace structure formed by dynamic recrystallization in HfNbTaTiZr BCC refractory high entropy alloy,” Acta Materialia, vol. 183, pp. 64-77, Jan. 2020, doi: 10.1016/j.actamat.2019.11.001.

[39] M. Kini and A. H. Chokshi, "The influence of titania on creep in superplastic zirconia," Journal of the American Ceramic Society, vol. 93, no. 6, pp. 1725-1731, Jun. 2010, doi: 10.1111/j.1551-2916.2010.03617.x.

[40] E. Schwaighofer, B. Rashkova, H. Clemens, A. Stark, and S. Mayer, "Effect of carbon addition on solidification behavior, phase evolution and creep properties of an intermetallic $\beta$ stabilized $\gamma$-TiAl based alloy," Intermetallics, vol. 46, pp. 173-184, Mar. 2014, doi: 10.1016/j.intermet.2013.11.011.

[41] Q. Wang, L. Zeng, H. Ding, R. Chen, J. Guo, and H. Fu, "Microstructures and mechanical properties of directionally solidified C-containing $\gamma$-TiAl alloys via electromagnetic cold crucible," Intermetallics, vol. 113, Oct. 2019, doi: 10.1016/j.intermet.2019.106587. 
[42] H. Fang et al., "Effects of niobium on phase composition and improving mechanical properties in TiAl alloy reinforced by Ti2AlC," Intermetallics, vol. 115, Dec. 2019, doi: 10.1016/j.intermet.2019.106630.

[43] W. Sprengel, T. Yamada, and H. Nakajima, "Interdiffusion in binary $\beta$-titanium alloys," Defect and Diffusion Forum, vol. 143-147, pp. 431-436, 1997, doi: 10.4028/www.scientific.net/ddf.143-147.431.

[44] G. H. Edward and M. F. Ashby, "Intergranular fracture during power-law creep," Acta Metallurgica, vol. 27, no. 9, pp. 1505-1518, 1979, doi: 10.1016/0001-6160(79)90173-1.

[45] T. Pollock, "Nondestructive Evaluation (NDE) Technology Initiatives Program (NTIP). Delivery Order 0041: Advanced Processing of Novel Ni-Based Single Crystal Alloys," 2004, Accessed: Sep. 16, 2020. [Online]. Available: https://apps.dtic.mil/sti/citations/ADA427337.

[46] E. Pink, "Physical significance and reliability of Larson-Miller and Manson-Haferd parameters," Materials Science and Technology (United Kingdom), vol. 10, no. 4, pp. 340-346, 1994, doi: $10.1179 /$ mst.1994.10.4.340.

[47] M. Beschliesser et al., "Designed fully lamellar microstructures in a $\gamma$-TiAl based alloy: Adjustment and microstructural changes upon long-term isothermal exposure at 700 and $800{ }^{\circ} \mathrm{C}$," Materials Science and Engineering A, vol. 329-331, pp. 124-129, Jun. 2002, doi: 10.1016/S09215093(01)01545-3.

[48] G. Sundararajan, "The Monkman-Grant relationship,” Materials Science and Engineering A, vol. 112, no. C, pp. 205-214, Jun. 1989, doi: 10.1016/0921-5093(89)90360-2.

[49] F. Dobeš, K. M Milička. Materials Science and Engineering A, "On the Monkman-Grant relation for small punch test data," Elsevier, Accessed: Sep. 16, 2020. [Online]. Available: https://www.sciencedirect.com/science/article/pii/S092150930101975X. 
[50] C. Phaniraj, B. Choudhary, K. Rao, B. Raj. Scripta Materialia, 2003, "Relationship between time to reach Monkman-Grant ductility and rupture life," Elsevier, Accessed: Sep. 16, 2020. [Online]. Available: https://www.sciencedirect.com/science/article/pii/S1359646203000216.

[51] H. Ali, M. Tamin. J. of Nuclear Materials, 2013, "Modified Monkman-Grant relationship for austenitic stainless steel foils," Elsevier, Accessed: Sep. 16, 2020. [Online]. Available: https://www.sciencedirect.com/science/article/pii/S0022311512004709.

[52] MONKMAN F. C., “An Empirical Relationship between Rupture Life and Minimum Creep Rate in Creep Rupture Tests," Proc. ASTM, vol. 56, pp. 91-103, 1956, Accessed: Sep. 16, 2020. [Online]. Available: https://ci.nii.ac.jp/naid/10006401917.

[53] J. Manuel, A. Calderon, and M. L. Bañuelos, "An extension of the Monkman-Grant model for the prediction of the creep rupture time using small punch tests," Springer, doi: 10.1007/s11340-0149927-6.

[54] M. Menon, H. Fang, D. Wu, M. Jenkins, M. Ferber. J. American Ceramic Society, 1994, "Creep and Stress Rupture Behavior of an Advanced Silicon Nitride: Part III, Stress Rupture and the Monkman-Grant Relationship,” Wiley Online Library, Accessed: Sep. 16, 2020. [Online]. Available: https:/ceramics.onlinelibrary.wiley.com/doi/abs/10.1111/j.1151-2916.1994.tb05397.x.

[55] M. Evans, "Further analysis of the Monkman-Grant relationship for 2-25Cr-1Mo steel using creep data from the National Research Institute for Metals," Materials Science and Technology, vol. 15, no. 1, pp. 91-100, 1999, doi: 10.1179/026708399773003367.

[56] W. Gon Kim, S. Ho Kim, and W. Seog Ryu, "Evaluation of Monkman-Grant parameters for type 316LN and modified 9Cr-Mo stainless steels," Article in Journal of Mechanical Science and Technology, vol. 16, no. 11, pp. 1420-1427, 2002, doi: 10.1007/BF02985134. 
